\title{
THE REINFORCING ROLE OF ALTERNATIVE GOVERNANCE STRATEGIES IN MANAGING ICT FIRMS' PARTNER NETWORKS
}

\author{
Chris Storey, Cass Business School, City University London, United Kingdom.
}

\begin{abstract}
The effective management of indirect sales channels have significant profit implications for many companies. This is true, even more so, in the information and communication technology (ICT) sector, where a significant portion of the sales for the seller go through the business partner, the reseller. An effective partner management strategy has been widely acknowledged as essential part of companies' operating strategies in high technology markets (De Ruyter, Moorman \& Lemmink, 2001). Governance refers to the regulation of a system. Partnership governance is defined as the mechanisms suppliers have in place to encourage and control the behavior and ultimately performance of its partners. Choosing effective governance mechanisms are essential for successful partner-supplier relationships (Jap \& Ganesan, 2000; Li et al., 2010). The aim of this research is to extend our understanding of governance theory and to understand the most effective mix of governance mechanisms for achieving partner performance.
\end{abstract}

Governance theory distinguishes between those mechanisms that are more monitoring or control based and also those that are based on influence aimed at positive reinforcement (Gilliland et al 2010; Li et al., 2010). Formal governance mechanisms are rooted in agency theory where actors need to be formally controlled through monitoring of performance and setting of clear goals (Eisenhardt, 1989). In this research we identify certification as the formal control mechanism of ICT partners. We define certification as supplier's requirements on partner organizations for attaining proficiency and competency in the supplier's line of products or services via a standardized formalized process.

Recently research has stressed the importance of informal governance mechanisms that help parties expand the level of value created by the exchange (Burket et al., 2012). ). These indirect controls aim at achieving behavioral change by altering the partner's perceptions (Zablah, Johnston \& Bellenger, 2005). Relationship bonds, the close interpersonal relationship between a partner and its the supplier, will influence the behaviour of the partner and the supplier.

We propose a 3rd type of governance mechanism that expands the notion of social ties guiding a relationship to the network of partners that the firm manages. By creating a partner community the supplier can build up a shared understanding between partners. This shared understanding will influence the behaviour of individual partners.

The three governance mechanisms, as means of regulating or influencing behaviour to achieve desired goals, will have direct influences on relationship performance. However the notion of adaptive governance suggests that the effectiveness of a governance mechanism is contingent not only on the activity being governed but also on the desired outcomes of the activity (Gilliland, 2003). Therefore the influence of the governance mechanisms will not be equal across the performance dimensions. Building on contingency theory the "fit" between different governance mechanism will have an additional impact on relationship performance (Venkatraman 1989; Lee et al. 2011). Three key dimensions of relationship performance are considered: harmony, commitment and economic satisfaction.

A conceptual model is built which is tested by a key informant survey. was used to test the model. Data was collected from 151 partners from leading ICT suppliers in the United Kingdom and Ireland.

Direct links were found between partner relationship bonds, partner community and harmony and economic satisfaction. However these two governance mechanism did not have a direct link to relationship commitment. Social influence governance mechanisms do not increase commitment directly. Rather they increase commitment by developing the relationship. Rather commitment is increased by certification which helps lock a partner to its supplier. Surprisingly certification did not increase economic satisfaction. For economic satisfaction relationship bounds had a positive interaction with partner community but a negative one with certification showing the importance of having the correct mix of governance mechanisms.

References available upon request. 